\title{
Process optimisation of low-caffeine coffee using steam treatment
}

\author{
Riyan Anggriawan ${ }^{\mathrm{a}, \mathrm{b}, *}$, Ali Maksum ${ }^{\mathrm{c}}$, Fransisca Wijaya ${ }^{\mathrm{a}}$, Ike Sitoresmi Mulyo Purbowati ${ }^{\mathrm{c}}$ \\ * Corresponding author \\ E-mail address: riyan.anggriawan@pmbs.ac.id
}

${ }^{a}$ Food Business Technology, School of Applied Science, Technology, Engineering and Mathematics (STEM), Prasetiya Mulya University, Tangerang 15339, Indonesia

${ }^{b}$ Research, Community Service and Industry Relation Section, STEM, Prasetiya Mulya

University, Tangerang 15339, Indonesia

'Department of Agricultural Technology, Jenderal Soedirman University, Purwokerto, 53123, Indonesia

\begin{abstract}
In addition to being a source of freshener, coffee has an enormous possibility to be developed as a source of antioxidants for functional beverages. However, efforts to increase the value added of coffee as a health functional drink are still hindered by the presence of high level of caffeine, which is thought to have adverse effects on health, especially for coffee lovers who are vulnerable to caffeine. This study aims to optimise the steaming duration to produce low caffeine coffee while maintaining the sensory attributes and antioxidant compounds contained in it. Indonesian Arabica (Leksana variety) green coffee beans were steamed with multi-level steaming durations $(0,20,40,60$ and $80 \mathrm{~min}$ ) followed by roasting (medium-dark roast degree), grinding, and brewing (espresso method). The results indicate that caffeine content in the coffee was inversely proportional to the steaming duration. The lowest caffeine content was obtained from the treatment of 80 min steaming with a decrease of caffeine level up to $28.73 \%$. However, the longer process of steaming caused a significant decrease in polyphenol content and antioxidant activity. The hedonic test shows that the steaming treatment of coffee can increase preferences of panellists. There were two driving attributes that influence the overall liking of coffee, namely: bitterness and aftertaste. Coffee obtained from the treatment of 60 min steaming was most preferred by panellists. The results of APLSR biplot mapping show that there was a big change in almost all attributes in the coffee samples after 40 min steaming.
\end{abstract}

\section{Keywords:}

Antioxidant activity, Arabica coffee, Caffeine reduction, Steaming times 


\section{Introduction}

The role of coffee as a source of antioxidants is not widely known by the community. In fact, coffee contains bioactive compounds, especially polyphenols which function as antioxidant compounds, one of which is chlorogenic acid along with its derivatives namely pcoumaric acid trigonelline, and ferulic acid (Affonso et al., 2016). Yen et al. (2005) stated that coffee has an antioxidant activity four times higher than green tea. The health benefits of antioxidants are well known since these compounds are able to neutralize free radical compounds. As a lot of researchers have previously reported, the presence of free radicals at high concentrations in the body can trigger oxidative stress that can cause damage to cells and tissues, which is the primary cause of many kinds of diseases such as cancer, cataracts, hypertension, arteriosclerosis, diabetes, immune decline, neurodegenerative diseases and other health problems (Sharma, 2014). Coffee consumption was found to add the total intake of polyphenols in one's diet so that it was thought to reduce the risk of health problems (Grosso et al., 2014). This finding is also in line with epidemiological study which showed that coffee consumption could prevent various degenerative diseases (Bae et al., 2014). However, for some people, especially those with sensitive stomach, coffee consumption must be avoided due to the negative effects of caffeine.

Caffeine compound is recognized as alkaloid due to its origin from secondary metabolites consisting of purine nucleotides with heterocyclic nitrogen atoms (de Paula and Farah, 2019). Caffeine compound contained in coffee increases adrenaline so as to refresh people who drink it (Bettram et al., 2014). Caffeine was found to increase systolic pressure by $17 \%$ and heart rate (Geethavani et al., 2014). Excessive caffeine consumption could be harmful to health, for example increasing brain tension, delirium, stress, symptoms of poisoning (Willson, 2018), and increasing the secretion of gastric acid (Liszt et al., 2017). In addition, other negative effects such as nausea, anxiety, poor fetal growth, and bone loss were related with excessive caffeine consumption (de Mejia et al., 2014). Caffeine also influences acute increase in blood pressure for 3 hours in people suffering from hypertension (Mesas et al., 2011). Therefore, it is necessary to find the right solution to minimize the negative effects of caffeine, as well as to improve the image of coffee as a drink that is safer to consume, even by patients with hypertension and sensitive stomach.

One of the solutions that can be done is to reduce or even eliminate the caffeine compound in coffee beans called decaffeination. This process is able to reduce caffeine compound without reducing the odor and taste of coffee and maintain the functional properties 
of the drink. Water steam treatment method was chosen in this study. Caffeine solubility increased significantly when it was dissolved in water with high temperatures, so that it was effective to use for the decaffeination process (Pietsch, 2017). Heat can break the bonds of caffeine ions and other compounds, so that caffeine will be free and loose in water (Peker et al., 2004). This method is relatively simple, inexpensive, and more environmentally friendly so it has the potential to be widely applied to small-scale coffee businesses in developing countries. The disadvantage of this method is that the components of compounds other than caffeine are also dissolved in water such as sugar which is a component of aroma (Pietsch, 2017). Therefore, optimisation of the caffeine reduction process is needed so that there are not too many components other than caffeine which are not dissolved during the process. In this study, the researchers examined the most optimal steaming duration to reduce caffeine level in Arabica coffee by considering several important properties including sensory aspect that might be affected by the method.

\section{Materials and Methods}

\section{Sample preparation}

Wet processed Arabica (Leksana variety) green beans with first grade was obtained from a local coffee plantation at the slopes of Mt. Slamet, Banyumas Regency, Indonesia (with moisture content $11.37 \pm 0.65 \%$, wet basis). The green coffee bean (80 g) measured using analytical balance M5-HPB 414Ai (BEL Engineering, Italy) was submitted to steam treatment in steamer MCM-606 (Miyako, Indonesia) following a completely randomized design with different steaming time $(20,40,60$, and $80 \mathrm{~min})$ as the independent variable. An untreated coffee bean $(0 \mathrm{~min})$ was maintained as a control variable. Therefore, there were 5 levels of treatment, namely: $t_{0}=0 \mathrm{~min}(\mathrm{control}), t_{20}=20 \mathrm{~min}, t_{40}=40 \mathrm{~min}, t_{60}=60 \mathrm{~min}$, and $t_{80}=80$ $\min$. The steaming temperature was maintained at $100^{\circ} \mathrm{C}$ (atmospheric pressure).

The steamed coffee beans were dried using food dehydrator model 616 (Ariete, Indonesia) for 1 hour. The temperature was set at $60^{\circ} \mathrm{C}$ to prevent excessive heating. The drying operation was done mainly to prevent moisture from interrupting the roasting process. Afterwards, the dried green coffee beans were roasted using roaster SCR 301 (Bar Well, Indonesia) for $16 \mathrm{~min}$ at $220^{\circ} \mathrm{C}$. With this temperature and duration, the coffee would reach the medium-dark roast degree. The roasted coffees were middle ground using food blender 7011S (Waring, USA) and stored in sealed flasks with silica gel (food grade) at room temperature for 
analysis. Espresso brewing method was chosen on the basis of its consumption all over the world. Espresso coffee samples were prepared using espresso maker CRM 2008 (CRM, China). The researchers used ten grams of powdered coffee and brewed it with distilled water $(100 \mathrm{~mL})$ with the following conditions: ground coffee and water ratio was 1:10 (w/v); water temperature of $95^{\circ} \mathrm{C}$; and relative pressure of $5 \mathrm{~atm}$.

\section{Chemicals}

All the chemicals (at analytical grade) used in this research were acquired based on Sigma-Aldrich (St Louis, USA). All the solvents had HPLC grade of purity and purchased from Merck (Darmstadt, Germany).

\section{Measurement of ground coffee physical attributes}

\section{Browning index (BI) analysis}

The measurement of the physical appearance of ground coffee especially its colour was performed using a chroma meter (Minolta CR-310, Japan). Colour detection followed the provided manual instructions. Measurements were made in triplicate. Chroma meter tool used the Hunter colour notation system characterized by 3 parameters a* (redness or greenness), b* (blueness or yellowness), and L* (whiteness or darkness). Maskan (2001) stated that these values were then used in the BI formula:

$$
\begin{gathered}
x=\frac{(a+1.75 L)}{(5.645 L+a-3.012 b)} \\
\mathrm{BI}=\frac{[100(x-0.31)]}{0.17}
\end{gathered}
$$

Moisture content (MC) analysis

MC determination of powdered coffee was performed by using the AOAC method 10.102 (AOAC, 2016). The MC result was presented as a $\mathrm{g} / 100 \mathrm{~g}$ dry basis (db).

Measurement of $\mathrm{pH}$, chemical and antioxidant properties for coffee brew

\section{Determination of $p H$}


An amount of $40 \mathrm{~mL}$ of coffee brew was cooled to room temperature before used for $\mathrm{pH}$ measurement. The $\mathrm{pH}$ measurement was carried out using a digital $\mathrm{pH}$ meter CG 842 (Schott, Germany) and this tool had been calibrated by using acetate buffer ( $\mathrm{pH} 4$ ) and phosphate buffer ( $\mathrm{pH}$ 7). Then, the electrode was dipped for a while into the sample filtrate to find out the measured $\mathrm{pH}$. Measurements were made in triplicate.

\section{Analysis of total phenolic content (TPC)}

TPC in the coffee brew was assessed using Folin-Ciocalteu protocol firstly explained by Shetty et al. (1995) with minor modification. The standard used here was gallic acid. TPC was defined as gallic acid equivalent (GAE).

\section{Antioxidant activity (DPPH IC 50 ) analysis}

Scavenging activity for free radical of the coffee brew was assessed by using DPPH (2,2-diphenyl-1-picrylhydrazyl) in accordance with the protocol explained by Yen and Chen (1995) with minor modification. Preparation mixture as follows; A sample blank (sample with no DPPH solution) $=750 \mu \mathrm{L}$ sample $+750 \mu \mathrm{L} \mathrm{EtOH}$; A control (DPPH solution by excluding sample) $=750 \mu \mathrm{L}$ DPPH $0,16 \mathrm{mM}+750 \mu \mathrm{L} \mathrm{EtOH}$; and A sample (DPPH solution plus test sample $)=750 \mu \mathrm{L}$ sample $+750 \mu \mathrm{L}$ DPPH $0.16 \mathrm{mM}$. Briefly, the mixture was then shaken intensely and was put to standard room temperature in darkness for $30 \mathrm{~min}$. The changes of the sample absorbance were then recorded at $517 \mathrm{~nm}$ with a spectrophotometer (1700 spectrophotometer, Shimadzu). The performance to scavenge free radical was determined according to formula stated below.

DPPH radical scavenging activity $(\%)=$

$$
\left[1-\left(\frac{\text { A sample }- \text { A sample blank }}{\text { A control }}\right)\right] \times 100
$$

DPPH $\mathrm{IC}_{50}$ value was determined by finding the coffee concentration which provided a $50 \%$ reduction of free radical concentration.

\section{Caffeine content analysis}

Caffeine content was analysed with high performance liquid chromatography (HPLC Shimadzu, UV-VIS detector) for quantification using VP ODS C18 Column with internal diameter of $4.6 \mathrm{~nm}$, pore size of $5 \mu \mathrm{m}$ and length of $150 \mathrm{~mm}$ (Thermo scientific). The HPLC 
conditions included constant $1 \mathrm{~mL} / \mathrm{min}$ flow rate with column temperature at $40^{\circ} \mathrm{C}$ and a $\mathrm{UV}$ detector regulated at $254 \mathrm{~nm}$. The mobile phase used was methanol:water (20:80 v/v) which both were HPLC grade. Briefly, a $0.45 \mu \mathrm{m}$ Milipore filter was utilized to filter the coffee brew (Merck Milipore, Germany), and $20 \mu \mathrm{L}$ of the sample that had been filtered was submitted for HPLC analysis. The amount of caffeine was determined from the peak area based on a standard caffeine curve $\left(\mathrm{LoD}=0.9 \mathrm{mg} / \mathrm{L} ; \mathrm{R}^{2}=0.995\right)$.

\section{Sensorial evaluation of coffee brew}

All four steam-treated beans and control were prepared as espressos using espresso maker for acceptance (hedonic) test, as previously described in sample preparation section. Ten millilitres of espresso would be poured into small glass with the same volume and labelled using three-digit random code. The respondents consisted of 50 panellists who were regular consumers of espresso coffee. They were 18 to 35 years old consisting of $42 \%$ women and $58 \%$ men. Each panellist was given espressos from the 4 steam-treated beans and control along with the response sheet. Panellists were asked to fill out a response sheet followed by a liking score scaling from 1-9 (1 = dislike very much, $9=$ like very much $)$ to the samples based on each panellist's level of acceptance on each attribute. The attributes that were tested included colour, coffee aroma, bitterness, aftertaste, and overall liking. Panellists were obligated to eat crackers to neutralize palate after testing. Table 1 describes the attributes.

Table 1 Attribute description

\begin{tabular}{|c|c|}
\hline Attribute & Description \\
\hline Coffee odor/aroma & The distinct smell due to coffee products (Stokes et al., 2017) \\
\hline Bitterness & $\begin{array}{l}\text { Sensation generated from bitter substances present in coffee, which is } \\
\text { brewed using espresso method. This sensation is especially } \\
\text { recognized at the back part of the tongue (Barahona et al., 2020) }\end{array}$ \\
\hline After taste & $\begin{array}{l}\text { Post-tasting flavours that settle in the mouth after the coffee drink is } \\
\text { tasted. These flavours can be defined as pleasant or unpleasant. e.g. } \\
\text { astringent, acidic, burnt taste (Barahona et al., 2020) }\end{array}$ \\
\hline Overall liking & $\begin{array}{l}\text { Summary of the panellists' assessments related to overall impression } \\
\text { of the sample (Barahona et al., 2020) }\end{array}$ \\
\hline Colour & The brown colour of coffee samples (Geel et al., 2005) \\
\hline
\end{tabular}

\section{Statistical analysis}

All analyses (physicochemical and antioxidant properties) were performed in quadruplicate $(n=4)$. The data were elaborated as means \pm standard error. One-way ANOVA was applied to calculate the significant differences between the means by using the IBM SPSS 
Statistic 20 software (SPSS Inc., Chicago, IL, USA). The significance was assessed at level of $p<0.05$. Tukey post hoc test was utilized to compare the mean of each sample.

The APLSR (ANOVA-Partial Least Squares Regression) multivariate analysis was performed to obtain the relationship between the various steaming time and the panellists preference. All properties profiling was analysed using APLSR biplot with Origin Pro 2019 software (OriginLab Inc., Northampton, MA, USA).

\section{Results and Discussion}

\section{Moisture content and browning index of powdered coffee}

The moisture content value of powdered coffee in this research is shown in Table 2. The moisture content of ground coffee showed a notable increase $(p<0.05)$ along with an increase in steaming time. The highest moisture content was found in samples $t_{60}$ and $t_{80}$, namely $2.90 \pm 0.31$ and $3.16 \pm 0.19 \mathrm{~g} / 100 \mathrm{~g}$, respectively. Even so, the moisture content of ground coffee produced is still in accordance with the Indonesian National Standard (SNI 01$3542-2004$ ), stating that the maximum moisture content of ground coffee is $7 \%$. Increased coffee moisture content is due to condensation of water vapor to the surface and pores of coffee beans (Malkov et al., 2002). The steaming treatment is thought to cause the pores of the coffee beans to widen so that the result of condensation of water vapor enters through the pores of the coffee beans in high amounts (Widyotomo et al., 2009). Jokanovic et al. (2012) stated that the water content in coffee beans can affect the level of fragility of the beans and the grinding process which can then affect the coffee extraction process.

Tabel 2 Moisture content, and browning index of the powdered coffee obtained from different steaming times treatment

\begin{tabular}{ccc}
\hline Steaming Times & Moisture Content $(\mathrm{g} / 100 \mathrm{~g})$ & Browning Index \\
\hline $0 \min \left(t_{0}\right)$ & $2.33 \pm 0.23^{\mathrm{c}}$ & $128.00 \pm 6.57^{\mathrm{a}}$ \\
$20 \min \left(t_{20}\right)$ & $2.40 \pm 0.14^{\mathrm{c}}$ & $119.04 \pm 7.1^{\mathrm{a}}$ \\
$40 \min \left(t_{40}\right)$ & $2.64 \pm 0.22^{\mathrm{bc}}$ & $90.17 \pm 4.19^{\mathrm{b}}$ \\
$60 \min \left(t_{60}\right)$ & $2.90 \pm 0.31^{\mathrm{ab}}$ & $71.74 \pm 3.44^{\mathrm{c}}$ \\
$80 \min \left(t_{80}\right)$ & $3.16 \pm 0.19^{\mathrm{a}}$ & $60.92 \pm 3.84^{\mathrm{c}}$ \\
\hline
\end{tabular}

Mean of four data \pm standard deviation (sd).

Values written with different superscript in the same column showed a significant difference in Tukey's test $(p<0.05)$. 
Browning index (BI) shows brown colour develops as a result of non-enzymatic browning (maillard) during roasting. BI values indirectly indicate the amount of brown pigments (melanoidins) formed during browning reactions (Maskan et al., 2001). As shown in Table 2, the value of ground coffee BI showed a notable decrease $(p<0.05)$ along with the extend in steaming duration. Highest BI values were found in the samples $t_{0}$ and $t_{20}$, namely $128.00 \pm 6.57$ and $119.04 \pm 7.11$, respectively. The steaming treatment is thought to cause leaching of the sugar and amino acid components of coffee beans. The longer the steaming process causes more components of sugar and amino acids to leach leading the maillard reaction to occur less intensively during the roasting. Maillard reaction can be defined as a browning reaction due to a reaction between sugar and amino acids or protein. It begins with the reaction between the aldehyde group or ketone in sugar with the primary amine group on amino acids or protein to form glycosylamine (schiff base). Afterwards, it is followed with an Amadori rearrangement that will convert glycosylamine to a semi-finished product. Furthermore, intermediate products are involved in an intricate reaction (dehydration and polymerization) to form various volatile compounds and brown pigments of melanoidin (BeMiller and Huber, 2008).

\section{pH and caffeine content of coffee brew}

Table 3 shows that the $\mathrm{pH}$ value had a significant increase $(p<0.05)$ along with the longer steaming time. The lowest $\mathrm{pH}$ values were found in samples $t_{0}$ and $t_{20}$ with $\mathrm{pH}$ values of $5.14 \pm 0.05$ and $5.26 \pm 0.07$, respectively. Meanwhile, the highest $\mathrm{pH}$ value was found in sample $t_{80}$ with a $\mathrm{pH}$ value of $6.13 \pm 0.10$. It is considered to be due to the loss of various organic acids during the steaming process. There are various types of organic compounds with low molecular weight contained in coffee including carboxylic acids such as succinic, malic, citric, gluconic and quinic acids. These organic acids are polar and easily dissolve in water (Rao and Fuller, 2018). In addition, the longer steaming is considered to cause leaching of proteins and more intensive coffee bean sugar which causes the formation of various types of acids during roasting being inhibited. Ginz et al. (2000) stated that acidity can also be produced from the degradation of proteins and sugars into acidic compounds during the roasting.

Table 3 shows that the caffeine content of coffee decreased significantly $(p<0.05)$ along with longer heating duration. The lowest caffeine content was obtained in sample $t_{80}$ of $0.84 \pm 0.015 \mathrm{~g} / 100 \mathrm{~g}$. When compared to the control $\left(t_{0}\right)$, the decrease in caffeine in $t_{80}$ sample reached $28.73 \%$. Steaming plays a role to separate caffeine bonds with chlorogenic acid located 
in the cytoplasm and cell walls that are difficult to dissolve in water. The separation of the bonds between caffeine and chlorogenic acid makes caffeine more soluble in water (Peker et al., 2004). The longer the steaming time, the more caffeine being released from chlorogenic acid. Caffeine content decreased during steaming because caffeine (which is not bound/free) has the same polar nature as water. The caffeine polarity is due to there are two carbonyl groups together with free electron pairs of nitrogen so that caffeine can dissolve in water (Edward et al., 2015). However, the reduction in caffeine content is still relatively low because caffeine has a thin, flat surface so that it is easily hydrated which causes water splitting and becoming somewhat nonpolar (Tavagnacco et al., 2011).

Table $3 \mathrm{pH}$, total pehenolic content (TPC), DPPH IC50, and caffeine content of coffee brew obtained from different steaming times treatment

\begin{tabular}{ccccc}
\hline Steaming Times & $\mathrm{pH}$ & $\begin{array}{c}\mathrm{TPC} \\
(\mathrm{g} \mathrm{GAE} / 100 \mathrm{~g})\end{array}$ & $\begin{array}{c}\text { DPPH IC } \\
(\mathrm{mg} / \mathrm{mL})\end{array}$ & $\begin{array}{c}\text { Caffeine Content } \\
(\mathrm{g} / 100 \mathrm{~g})\end{array}$ \\
\hline $0 \min \left(t_{0}\right)$ & $5.14 \pm 0.05^{\mathrm{d}}$ & $5.59 \pm 0.17^{\mathrm{a}}$ & $10.21 \pm 0.55^{\mathrm{d}}$ & $1.17 \pm 0.021^{\mathrm{a}}$ \\
$20 \min \left(t_{20}\right)$ & $5.26 \pm 0.07^{\mathrm{d}}$ & $5.38 \pm 0.05^{\mathrm{ab}}$ & $11.22 \pm 0.48^{\mathrm{d}}$ & $1.08 \pm 0.013^{\mathrm{b}}$ \\
$40 \min \left(t_{40}\right)$ & $5.47 \pm 0.05^{\mathrm{c}}$ & $5.25 \pm 0.10^{\mathrm{b}}$ & $13.81 \pm 0.51^{\mathrm{c}}$ & $1.02 \pm 0.019^{\mathrm{c}}$ \\
$60 \min \left(t_{60}\right)$ & $5.93 \pm 0.05^{\mathrm{b}}$ & $4.35 \pm 0.26^{\mathrm{c}}$ & $19.90 \pm 0.57^{\mathrm{b}}$ & $0.93 \pm 0.020^{\mathrm{d}}$ \\
$80 \min \left(t_{80}\right)$ & $6.13 \pm 0.10^{\mathrm{a}}$ & $3.27 \pm 0.15^{\mathrm{d}}$ & $22.03 \pm 0.67^{\mathrm{a}}$ & $0.84 \pm 0.015^{\mathrm{e}}$ \\
\hline
\end{tabular}

Mean of four data \pm standard deviation (sd).

Values written with different superscript in the same column showed a significant difference in Tukey's test $(p<0.05)$.

Phenolic content and antioxidant activity of coffee brew

Referring to Table 3 it was known that the total phenol experienced a significant reduction $(p<0.05)$ along with the steaming time. The highest values of total phenol were found in samples $t_{0}$ and $t_{20}$ with of $5.59 \pm 0.17$ and $11.22 \pm 0.48 \mathrm{~g} \mathrm{GAE} / 100 \mathrm{~g}$, respectively. Meanwhile, the lowest total phenol was found in sample $t_{80}$ with a value of $3.27 \pm 0.15 \mathrm{~g}$ $\mathrm{GAE} / 100 \mathrm{~g}$. High steaming temperature triggers phenols damage because phenolic compounds are very susceptible to damage by high temperatures (Kalshone et al., 2019). The polyphenols also have hydrophilic properties so that they will dissolve with water vapor when they are steamed. The hydrophilic nature of phenols is due to the presence of hydroxyl groups that bind to benzene aromatic rings (Takebayashi et al., 2016).

Table 3 shows the antioxidant activity of coffee brew, where the longer the steaming time using hot water, the lower the antioxidant activity, as indicated by the DPPH $\mathrm{IC}_{50}$ value which evidnced a significant increase $(p<0.05)$. The decrease in activity of antioxidant was 
known by the higher concentration needed to achieve 50\% DPPH inhibition. The antioxidant compounds contained in coffee are dominated by polyphenolic compounds such as chlorogenic acid, trigonelline, p-coumaric acid, caffeine acid and ferulic acid (Affonso et al., 2016). This result is also in line with the research conducted by Kalshcne et al. (2019), which reported that trigonelline polyphenol that was partially liable for the antioxidant activity of coffee was negatively affected by steaming duration.

From the aforementioned explanation, it can be seen that a positive relationship was emerged between phenolic content and antioxidant activity. The total phenol contained in coffee decreased with the duration of steaming and it also occurred in antioxidant activity. This is due to the antioxidant compounds in coffee are dominated by polyphenolic compounds

\section{Sensory analysis}

The mean intensity and ANOVA result for the regression coefficient of APLSR for sensory acceptance data are shown in Table 4 . The $t_{60}$ example was the most acceptable with a mean value of 5.68 and significantly different from other samples $(p<0.01)$, followed with $t_{40}$ and $t_{80}$ with a mean value of 4.82 and 4.84 , respectively. The least accepted coffees were the $t_{20}$ sample and the control $\left(t_{0}\right)$ with a mean value of 4.72 and 4.48 , respectively. Table 2 shows that all samples were positively correlated with all attributes. From the table, it was found that the sample $t_{40}, t_{60}$ and $t_{80}$ were positively correlated significantly to the bitterness $(p<0.05)$, with the highest mean value of 5.64 was obtained by sample $t_{60}$. For colour attributes, only control that showed a significant and positive relationship $(p<0.001)$, and obtained the highest mean value of 6.04. Meanwhile, for aftertaste, a significant positive correlation was found in sample $\mathrm{t}_{60}$ with the highest mean value of 5.18.

Table 4 The average and $p$ value of regression coefficients from APLSR analysis for the hedonic test result

\begin{tabular}{|c|c|c|c|c|c|c|c|c|c|c|}
\hline \multirow[b]{2}{*}{$\begin{array}{l}\text { Steaming } \\
\text { times }\end{array}$} & \multicolumn{2}{|c|}{ Bitterness } & \multicolumn{2}{|c|}{ Color } & \multicolumn{2}{|c|}{ Aroma } & \multicolumn{2}{|c|}{ Aftertaste } & \multicolumn{2}{|c|}{ Overall liking } \\
\hline & $\begin{array}{c}\mathrm{P} \\
\text { value* }\end{array}$ & $\begin{array}{c}\text { Aver } \\
\text { age }\end{array}$ & $\begin{array}{c}\mathrm{P} \\
\text { value* }\end{array}$ & $\begin{array}{l}\text { Aver } \\
\text { age }\end{array}$ & $\begin{array}{c}\mathrm{P} \\
\text { value* }\end{array}$ & $\begin{array}{l}\text { Aver } \\
\text { age }\end{array}$ & $\begin{array}{c}\mathrm{P} \\
\text { value* }\end{array}$ & $\begin{array}{l}\text { Aver } \\
\text { age }\end{array}$ & $\begin{array}{c}\mathrm{P} \\
\text { value* }\end{array}$ & $\begin{array}{c}\text { Aver } \\
\text { age }\end{array}$ \\
\hline & $0.061^{\mathrm{ns}}$ & 4.02 & $0.000^{* * *}$ & 6.04 & $0.352^{\mathrm{ns}}$ & 5.2 & $340^{\mathrm{ns}}$ & 4.38 & $0.266^{\mathrm{ns}}$ & 4.48 \\
\hline $20 \mathrm{~m}$ & $0.466^{\mathrm{ns}}$ & 4.62 & $0.839^{\text {ns }}$ & 5.40 & $0.255^{\mathrm{ns}}$ & 6.06 & $0.310^{\mathrm{ns}}$ & 4.54 & $0.865^{\mathrm{ns}}$ & 4.76 \\
\hline $40 \mathrm{n}$ & $0.015^{*}$ & 4.26 & $0.873^{\text {ns }}$ & 5.20 & $0.266^{\mathrm{ns}}$ & 5.76 & $0.094^{\mathrm{ns}}$ & 4.96 & $0.798^{\mathrm{ns}}$ & 4.82 \\
\hline $60 \mathrm{~m}$ & $0.037^{*}$ & 5.64 & $0.101^{\mathrm{ns}}$ & 5.78 & $0.051^{\mathrm{ns}}$ & 5.94 & $0.045^{*}$ & 5.18 & $0.003^{* *}$ & 5.68 \\
\hline $80 \min \left(t_{80}\right)$ & $0.016^{*}$ & 4.80 & $0.067^{\mathrm{ns}}$ & 5.34 & $0.217^{\mathrm{ns}}$ & 5.54 & $0.057^{\mathrm{ns}}$ & 4.70 & $0.531^{\mathrm{ns}}$ & 4.84 \\
\hline
\end{tabular}

$*$ A $p$ value for revelant regression coefficient. The significance of regression coefficients: $* * * p$ $<0.001,{ }^{*} p<0.01,{ }^{*} p<0.05$, and ns=not significant. 
Fig. 1 illustrates the APLSR correlation loadings plot regarding hedonic evaluation of all coffee samples. The location of the attributes to the samples reveals the positive and negative drivers of acceptance (Meilgaard et al., 2016). The vector of the overall liking attribute was in the upper right quadrant close to sample $t_{60}$ as it is was the most preferred by panellists. Meanwhile, the control $\left(t_{0}\right)$ was in the lower left quadrant (the adversative direction) to the overall liking. This shows that control was least liked by consumers. Attributes that fall close to each other on the map are positively correlated with each other, and vice versa (Meilgaard et al., 2016). Fig. 1 shows the attributes that were significantly and positively correlated with overall liking were aftertaste and bitterness. In this case, with the increasing of the two attributes, the overall level of preference for coffee products will increase.

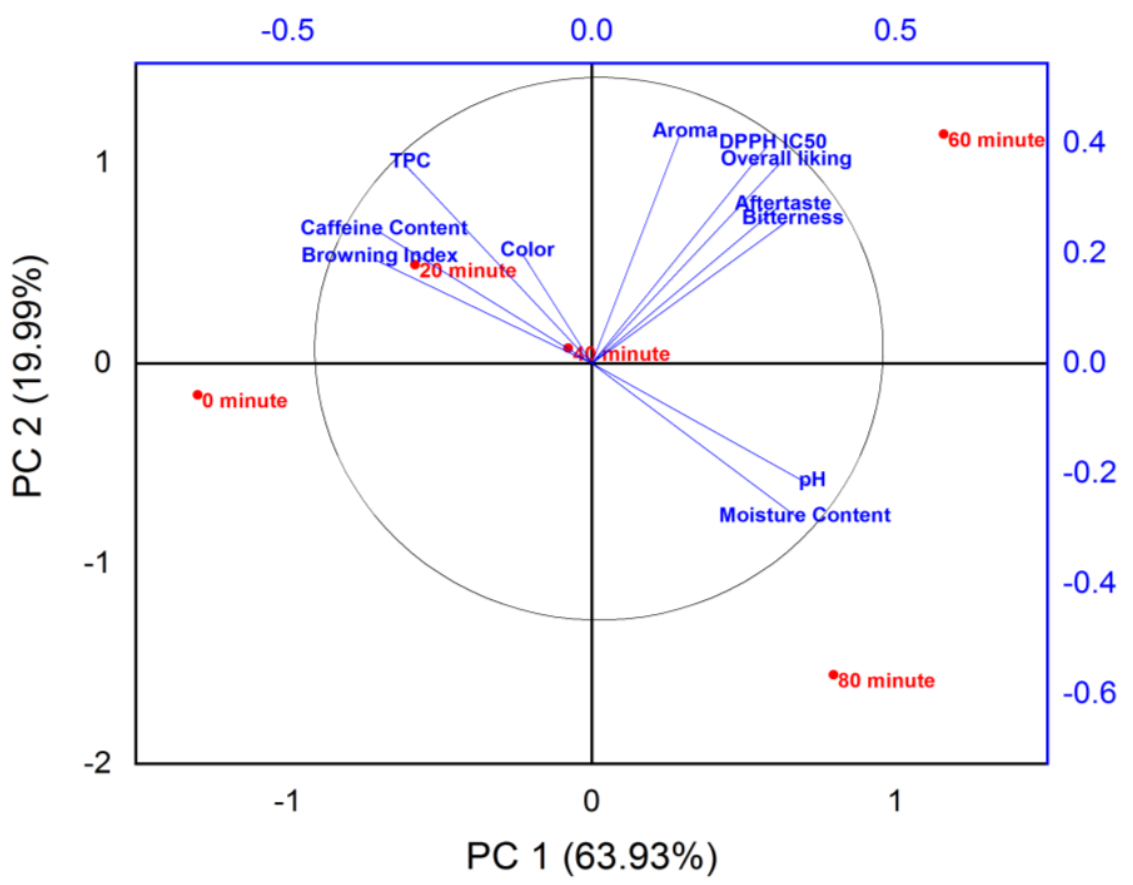

Fig. 1 APLSR biplot of all coffee properties changes from various steaming levels

The aroma of coffee is one of the important sensory attributes that influence quality (Illy and Viani, 2005). Although it is not significant, multivariate analysis revealed that there was a positive correlation of coffee aroma with each sample. This means that the more panellists like the aroma of coffee, then the overall coffee will be preferred as well. These study findings are in line with the study conducted by Stokes et al. (2017) which evidenced that filter coffees had a positive relationship with the preference of aroma, flavour and overall liking compared with instant coffee. On the other hand, Barahona et al. (2020) stated that smelling sensory properties have greater impact on buying intentions compared to tasting attributes. It 
means that the increasing preference for smelling attributes will increase the overall preference level, which in turn will influence buying intentions.

There are about 20-30 volatiles components in coffee that contribute to individual aroma (Sunarharum et al., 2014). The aroma of coffee is influenced by the processing stages, one of which is the preparation stage (Bhumiratana et al., 2011). Steaming process of coffee beans in this study was carried out in various time durations without pressure. However, this treatment did not result in differences of coffee aroma preferences among the samples. On the other hand, Baggenstoss et al. (2008) found that steam treatment with pressure combination had a dominant effect on roasting behaviour of coffee when some precursor compounds were extracted. Therefore, concentrations of various odorants showed differences relative to the concentration in coffee without any intervention, both in light and dark roasts. Meanwhile, there was still unclear sensory impact related to these differences in concentration and it should be clarified further using sensory tests and gas chromatography-olfactometry analysis.

Another attribute that has a positive correlation with overall preference is bitterness. Sample $t_{40}, t_{60}$ and $t_{80}$ were significantly and positively correlated with bitterness. One of the components that contributes to the bitter taste in coffee is caffeine (Buffo and Cardelli-Freire, 2004). The steaming process carried out in this study resulted in reduced caffeine content. The longer the steaming time, the lower the caffeine content (Table 3). This difference in bitterness was felt by panellists starting from sample $t_{40}$ which was steamed for $40 \mathrm{~min}$. Panellists felt less bitter taste in sample $t_{60}$ compared to control. The sample $t_{60}$ resulted in a higher level of preference. It means that the panellists liked the bitterness profile of the longer steam-treated coffee since the bitterness intensity of panellists lowered along with longer steaming time. These results are consistent with Geel et al. (2005) which conducted a sensory profiling for 11 instant coffees including decaffeinated coffee. One of the results was that decaffeinated coffee was felt by consumers to be less bitter than pure coffees.

Aftertaste is also a driving attribute for overall liking and it is positively correlated with overall liking. It means that the increased liking for aftertaste will also increase the overall liking for coffee. Aftertaste is very closely related to bitterness shown by vectors that form small angles (Fig. 1). This is because the panellists might also feel the bitter taste of coffee as an aftertaste. Aftertaste of coffee that is felt by many panellists is astringent and acidic taste. One of the components that contributes to astringent taste is chlorogenic acids (CGA) which contains secondary metabolites in coffee beans and contribute to the astringency (Sunarharum et al., 2014). Steaming process leads to lower CGA levels in decaffeinated coffee of 3-9\% compared to regular coffee. Although variations in the content of CGA of regular and 
decaffeinated coffees seem to be quite small, those variation may significantly affect the flavour characteristics, such as astringency (Farah et al., 2006).

Acidic taste is also felt as aftertaste by panellists. Acidic taste in coffee is due to the presence of organic acids contained in coffee. The steaming process causes a decrease in the organic acids contained in coffee as shown in Table 3. The $\mathrm{pH}$ of the sample increased along with the length of the steaming process. An increase in $\mathrm{pH}$ or a reduction in the amount of acid in coffee was felt by the panellists as indicated in higher aftertaste liking score in steamedcoffee samples compared to control, although it was not significant.

The steaming process affected consumer acceptance of coffee colour. The longer steaming time resulted in the browning index reduction of the samples (Table 2). This caused the colour of the coffee sample to be brighter than the control $\left(t_{0}\right)$. This colour difference has been seen starting from the sample with a steaming time of $20 \mathrm{~min}$. Sensory testing showed that panellists preferred darker than lighter brown coffee as indicated in score of preference obtained by control which was not treated with steaming. However, the result of multivariate analysis shows that colour liking attribute did not affect overall liking significantly. In this case, consumers tended not to pay attention to the colour of coffee in determining their preferences; in other words, colour is not a driving attribute for overall coffee liking.

\section{Critical steaming level analysis}

Biplot analysis (Fig. 1) distinguished the samples into different groups according to the steaming duration (PC1) and physicochemical, antioxidant and sensory attributes (PC2). Coffee samples were separated in three sites based on the steaming duration (PC1). Samples of 60- and 80-min steaming were placed on the right side and showed a higher $\mathrm{pH}$, moisture content, sensory reception, and higher DPPH IC 50 values. Samples of 0- and 20-min steaming were separated on the left side and showed a higher browning index, polyphenol, and caffeine content. The sample of 40 min steaming was located in a specific position in the middle of the image between the left- and right-side groups. This indicated that the critical steaming rate for changes in physicochemical and sensory attributes was at 40 min steaming. It is assumed that after $40 \mathrm{~min}$ the pores of the coffee beans opened optimally resulting in intensive leaching of various chemical components. This grouping shows that the steaming duration is crucial for the physicochemical, antioxidant, and sensory properties of coffee.

In conclusion, the long steaming treatment of coffee had a significant effect on physicochemical variables which included moisture content, browning index, $\mathrm{pH}$, total phenol, 
and caffeine content and had a notable effect also on antioxidant property. The longer the steaming time increased the moisture content and $\mathrm{pH}$, and decreased the Browning Index, caffeine content, total phenol, and antioxidant activity. The lowest caffeine content was obtained in the $t_{80}$ steaming treatment with a decrease in caffeine amount of up to $28.73 \%$, but its antioxidant activity also decreased to 2.2 times weaker compared to control. The coffee steaming process also caused significant differences in preferences between samples, especially with the aftertaste and bitterness attributes. These two attributes were positively correlated to overall liking. The effect of steaming process on the bitterness attribute could be felt after the steaming time of $40 \mathrm{~min}$, while the aftertaste could be felt after $60 \mathrm{~min}$. The difference of the colour was the fastest effect that could be seen by panellists starting from sample $t_{20}$. Sample $t_{60}$ was the most overall preferred by panellists indicated in the aftertaste and bitterness liking scores where the $t_{60}$ sample was higher than control. In the aroma attribute, the steaming process in coffee could also increase overall preferences, but not significantly. It can be concluded that the steaming treatment of coffee can increase consumer preferences for coffee because it can significantly increase the preference for coffee bitterness and aftertaste caused by reduced caffeine content and polyphenol. The results of APLSR biplot mapping show that there was a big change in almost all attributes in the coffee samples after 40 min steaming. Based on the consideration of changes in all the attributes, it is recommended that 60 min steaming is the most optimal duration for implementation.

\section{Conflict of Interest}

The authors declare that there are no conflicts of interest.

\section{Acknowledgements}

This article was partially funded by internal research grant from LPPM Jenderal Soedirman University and Prasetiya Mulya University. Authors also acknowledge local coffee plantation association in Banyumas regency for providing Arabica (Leksana variety) coffee beans.

\section{References}

Affonso, R.C.L., Voytena, A.P.L., Fanan, S., Pitz, H., Coelho, D.S., Horstmann, A.L., Ribeiro- 
do-Valle, R.M. 2016. Phytochemical composition, antioxidant activity, and the effect of the aqueous extract of coffee (Coffea arabica L.) bean residual press cake on the skin wound healing. Ox. Med. Cell Long. 2016: 10-21.

Association of Official Analytical Chemists (AOAC). 2016. Official methods of analysis of AOAC International. $20^{\text {th }}$ ed. AOAC International, United States.

Bae, J.H., Park, J.H., Im, S.S., Song, D.K. 2014. Coffee and health. Int. Med. Res. 3:189-91.

Barahona, I., Jaimes, E.M.S., Yang, J.B. 2020. Sensory attributes of coffee beverages and their relation to price and package information: A case study of Colombian customers' preferences. J. Food Sci. Nut. 8: 1173-1186.

Baggenstoss, J., Poisson, L., Kaegi, R., Perren, R., Escher, F. 2008. Roasting and aroma formation: Effect of initial moisture content and steam treatment. J. Agric. Food Chem. 56: 5847-5851.

Battram, D.S., Graham, T.E., Richter, E.A., Dela, F. 2005. The effect of caffeine on glucose kinetics in humans influence of adrenaline. J. Physiol. 569: 347-355.

BeMiller, J.N., Huber, K.C. 2008. Carbihydrates In: Damodaran S, Parkin KL, Fennema OR (Ed.), Fennema's food chemistry. CRC Press Inc., Boca Raton.

Bhumiratana, N., Adhikari, K., Chambers, I. 2011. Evolution of sensory aroma attributes from coffee beans to brewed coffee. LWT. 44: 2185-2192.

Buffo, R.A., Cardelli-Freire, C. 2004. Coffee flavor: An overview. Flavor Frag J. 19:99-104.

de Mejia, E.G., Ramirez-Mares, M.V. 2014. Impact of caffeine and coffee on our health. Trends in Endoc. Met. 25: 489-492.

de Paula, J., Farah, A. 2019. Caffeine consumption through coffee: Content in the beverage, metabolism, health benefits and risks. Beverages. 5: 37-87.

Edwards, Q.A., Lunat, I., Neale, L.D.G., Kulikov, S.M. 2015. Distribution of caffeine between selected water-organic solvent media. Int. J. Chem. Sci. 13:1218-1226.

Farah, A., de Paulis, T., Moreira, D.P., Trugo, L.C., Martin, P.R. 2006. Chlorogenic acids and lactones in regular and water-decaffeinated arabica coffees. J. Agric. Food Chem. 54:374-381.

Geel, L., Kinnear, M., de Kock, H.L. 2005. Relating consumer preferences to sensory attributes of instant coffee. J. Food Quality Pref. 16:237-244.

Geethavani, G., Rameswarudu, M., Reddy, R.R. 2014. Effect of caffeine on heart rate and blood pressure. Int. J. Sci. Res. Pub. 4:1-4.

Ginz, M., Balzer, H.H., Bradbury, A.G., Maier, H.G. 2000. Formation of aliphatic acids by carbohydrate degradation during roasting of coffee. Eur. Food Res. Tech. 211:404-410. 
Grosso, G., Stepaniak, U., Topor-Mądry, R., Szafraniec, K., Pająk, A. 2014. Estimated dietary intake and major food sources of polyphenols in the Polish arm of the HAPIEE study. Nutr. 30: 1398-1403.

Illy, A., Viani, R. 2005. Espresso coffee: The science of quality (2nd ed.). Elsevier Academic Press, London.

Jokanović, M.R., Džinić, N.R., Cvetković, B.R., Grujić, S., Odžaković, B. 2012. Changes of physical properties of coffee beans during roasting. Act. Per. Tech. 43: 21-31.

Kalschne, D.L., Viegas, M.C., De Conti, A.J., Corso, M.P., de Toledo Benassi, M. 2019. Effect of steam treatment on the profile of bioactive compounds and antioxidant activity of defective roasted coffee (Coffea canephora). LWT. 99: 364-370.

Liszt, K.I., Ley, J.P., Lieder, B., Behrens, M., Stöger, V., Reiner, A., Hochkogler, C.M., Köck, E., Marchiori, A., Hans, J., Widder, S. 2017. Caffeine induces gastric acid secretion via bitter taste signaling in gastric parietal cells. Proc. Nat. Acad. Sci. 114: 6260-6269.

Malkov, S., Tikka, P., Kuzmin, V., Baltakhinov, V. 2002. Efficiency of chip presteaming result of heating and air escape processes. Nord Pulp Paper Res. J. 17: 420-426.

Maskan, M. 2001. Kinetics of color changes of kiwifruit during hot air and microwave drying. J. Food. Eng. 48:169-175.

Meilgaard, M., Civille, G.V., Carr, B.T. 2016. Sensory Evaluation Techniques. New York, CRC Press.

Mesas, A.E., Leon-Muñoz, L.M., Rodriguez-Artalejo, F., Lopez-Garcia, E. 2011. The effect of coffee on blood pressure and cardiovascular disease in hypertensive individuals: a systematic review and meta-analysis. Am. J. Clinic Nut. 94: 1113-1126.

Peker, H., Srinivasan, M.P., Smith, J.M., McCoy, B.J. 2002. Caffeine extraction rates from coffee beans with supercritical carbon dioxide. AIChE J. 38: 761-70.

Pietsch, A. 2017. Decaffeination: process and quality. In Folmer, B. (Eds). The Craft and Science of Coffee. Academic Press, San Diego. pp. 225-243.

Rao, N.Z., Fuller, M. 2018. Acidity and antioxidant activity of cold brew coffee. Sci. Reports. 8: $1-9$.

Sharma, N. 2014. Free radicals antioxidant and disease. Bio Med. 6: 1-6.

Shetty, K., Curtis, O.F., Levin, R.E., Witkowsky, R., Ang, W. 1995. Prevention of vitrification asociated with in vitro shoot culture of oregano (Origanum vulgare) by Pseudomonas spp. J. Plant. Phy. 147: 447-51.

Stokes, C.N., O’Sullivan, M.G., Kerry, J.P. 2017. Hedonic and descriptive sensory evaluation of instant and fresh coffee products. Eur. Food. Res. Tech. 243: 331-340. 
Sunarharum, W.B., Williams, D.J., Smyth, H.E. 2014. Complexity of coffee flavor : A compositional and sensory perspective. J. Food. Res. Int. 62: 315-325.

Takebayashi, J., Oki, T., Watanabe, J., Yamasaki, K., Chen, J., Sato-Furukawa, M., TsubotaUtsugi, M., Taku, K., Goto, K., Matsumoto, T., Ishimi, Y. 2013. Hydrophilic antioxidant capacities of vegetables and fruits commonly consumed in Japan and estimated average daily intake of hydrophilic antioxidants from these foods. J. Food Comp. Anal. 29: 2531.

Tavagnacco, L., Schnupf, U., Mason, P.E., Saboungi, M.L., Cesàro, A., Brady, J.W. 2011. Molecular dynamics simulation studies of caffeine aggregation in aqueous solution. $\mathbf{J}$ Physic Chem. B. 115: 10957-10966.

Widyotomo, S., Mulato, S., Purwadaria, H.K., Syarief, A.M. 2009. Karakteristik proses dekafeinasi kopi Robusta dalam reaktor kolom tunggal dengan pelarut etil asetat. Pelita Perkebunan. 25: 101-125.

Willson, C. 2018. The clinical toxicology of caffeine: A review and case study. Tox. Reports. 5: $1140-1152$.

Yen, G.C., Chen, H.Y. 1995. Antioxidant activity of various tea extracts in relation to their anti-mutagenicity. J. Agric. Food. Chem. 43: 27-32.

Yen, W.J., Wang, B.S., Chang, L.W., Duh, P.D. 2005. Antioxidant properties of roasted coffee residues. J. Agric. Food. Chem. 53: 2658-2663. 